\title{
Attributions and moral judgments: Kohlberg's stage theory as a taxonomy of moral attributions
}

\author{
DONELSON R. FORSYTH and WILLIAM L. SCOTT \\ Virginia Commonwealth University, Richmond, Virginia
}

\begin{abstract}
Individuals who cheated or did not cheat on a test and observers who watched a test taker cheat or not cheat evaluated the causal importance of internal factors, external factors, and factors associated with each of the six stages of Kohlberg's model of moral development as determinants of the moral or immoral action. The results indicated that cheating was explained more in terms of the lower stages of moral thought, whereas the higher stages were used to account for not cheating, but few actor-observer differences were obtained. Overall, support was found for an attributional model of moral judgments that incorporates Kohlberg's stage model as a taxonomy of causes of moral and immoral actions, but the findings also suggest that Kohlberg's assumption that the stages are content free may be invalid.
\end{abstract}

An attributional approach to moral evaluation is based on the assumption that observers make inferences about the moral character or worth of others by gauging the relative influence of internal, personal factors versus external, situational pressures as determinants of moral or immoral behavior. As Kelley (1971) explained, in many respects moral evaluations parallel judgments made of individuals in achievement settings, for the actor "is not praised for doing good if it is something he wants to do anyway, or if there is strong social pressure to do so" (pp. 294-295). Instead, moral commendation occurs only if there are "strong evil forces that he must master in order to do good" (p. 295). In consequence, the attributor who witnesses a moral or immoral action must take into consideration a range of personal factors that may be causes-such as motives, intentions, moral character, or maliciousness-as well as external factors that may have so restricted the actor that inferences about moral worth cannot even be formulated.

The current investigation tested hypotheses derived from Kelley's (1971) attributional analysis of moral judgment, but extended the basic framework by operationalizing the personal causal factors that are salient in moralistic settings in terms of Kohlberg's (1969) stages of moral development. Although Kohlberg's theory typically is used to describe age-related changes in development, the six stages of the model can also be interpreted as different attributional explanations for action. At the lower stages, actions are explained through reference to relatively immature motivations-avoidance of punishment or desire for personal gain-and the mid-

Thanks are extended to Greg Lane, Ray Pope, and Nadine Scott for their contributions and comments, and to Ray Pope, Barbara Myers, Lynne Olsho, and Tom Leahey, who, along with the first author, served as rating-scale judges. The authors' mailing address is: Department of Psychology, Virginia Commonwealth University, Richmond, VA 23284. range explanations speak of the importance of maintaining conformity to others' expectations and rules. At the "highest" stages, Stages 5 and 6 , behavior and morality are more clearly linked, for the causal importance of internalized moral principles is emphasized at these two stages. Attributionally, Kohlberg's theory describes a taxonomy of person-centered causes that are salient explanations of immoral and moral action.

The utility of this approach was examined in the current study by assessing the causal inferences of actors who themselves cheated-or did not cheat-on a test and observers who watched a test taker cheat or not cheat. Overall, we predicted that refusing to cheat in the face of strong situational pressure would be taken as evidence of the actor's morality; hence, attributors would emphasize causes from Stages 5 and 6 when explaining noncheating. Cheating, in contrast, would be accounted for in terms of the lower stages, particularly the relatively "amoral" stages of 1 and 2. These differences, however, would be partially moderated by perspective effects. As is consistent with previous analyses of attributional asymmetries after success and failure (Ross \& DiTecco, 1975), we predicted that actors would be more likely than observers to (1) emphasize internal factors after not cheating and external factors after cheating and (2) cite higher causes when explaining their actions.

\section{METHOD}

\section{Subjects}

The 20 males and 51 females who participated were recruited from introductory psychology classes. All received class credit for their participation, and all were thoroughly debriefed immediately after their session.

\section{Procedure}

Actor subjects (12 males and 30 females) were told that, in order to study the impact of combined group effort on analytic ability, they would be working in two-person groups on a measure of this ability. One of the supposed subjects was in 
actuality a confederate, and he purposely broke his pencil while the male experimenter was absent from the room. On seeking a new pencil, the confederate "discovered"-but did not usethe answer key to the test.

Ten minutes later, the experimenter returned and, after examining the subject's and confederate's responses, asked them to work at the task until they had each solved at least three problems. This request was difficult to fulfill, however, because the problems consisted of 10- to 12-letter anagrams and could not be solved without reference to the key. Therefore, when the experimenter left the room for the second time, the confederate remarked "I don't know about you, but I'm taking some answers from this sheet. It's your decision, but I think you should take some too." For subjects in the "cheat" condition, the confederate continued to stress the need to cheat until the subject did, in fact, use the answer key (two refused). In the "no-cheat" condition, the confederate did not press the subject to cheat (one cheated anyway).

When the experimenter returned, he escorted the confederate from the room and then returned to tell the subject that he had discovered that cheating had, or had not, taken place. The subjects were then given the dependent-measures questionnaire, which contained the items presented in Table 1 . These items were selected from a larger pool of statements written to reflect the six stages of Kohlberg's (1969) theory. In developing the final instrument, each item in this larger pool was classified according to stage by five expert judges who were quite familiar with Kohlberg's theory. The final instrument included only those items that all five judges, working independently, had identified as reflecting a particular stage. In the cheat condition each causal statement began with "I cheated because," but in the no-cheat condition the stem read "I did not cheat because." The subjects indicated degree of agreement with each item using a scale ranging from 1 (completely disagree) to 9 (completely agree). In addition, the subjects also indicated the extent to which their behavior was caused by "basic personality characteristics" and "factors present in the experimental setting."

Observer subjects (8 males and 21 females) were shown a videotaped reenactment of the experimental session and then were given a questionnaire that differed from that given the actors only in the phrasing of the stem. Those who observed a subject cheat responded to items beginning with " $\mathrm{X}$ cheated because," whereas those who observed a noncheater responded to items starting with "X did not cheat because."

\section{RESULTS}

Preliminary analyses revealed no differences due to sex of subject, so this variable was eliminated from subsequent analyses. A 2 (behavior: cheat vs. no cheat) $x$ 2 (perspective: actor vs. observer) x 6 (stage: 1 through 6) repeated measures analysis of variance revealed a significant main-effect qualifying interaction of behavior and stage $[F(5,335)=17.87, \mathrm{p}<.0001]$. As the means shown in Table 1 indicate, the hypothesized pattern of attributions was obtained. First, whereas the Stage 1,2, and 3 explanations were equally emphasized by subjects in the cheat and no-cheat conditions, the higher stage explanations were more strongly endorsed when the action was not cheating than when it was cheating. Second, cheating was explained more in terms of the lower stages-particularly Stages 1 and 3-than in terms of the higher stages-particularly Stages 4 and 5. Third, the higher stages-especially Stage 6-were used to explain not cheating.

Although no effects due to perspective were obtained on the Kohlberg (1969) stage items, the perspective $\mathrm{x}$ behavior interaction reached significance on the attribution to "personal characteristics" item $[\mathrm{F}(1,67)=$ $4.61, \mathrm{p}<.05]$. The hypothesized actor-observer difference occurred in the cheat condition only, in which actors who cheated felt that their behavior was less due to personal characteristics than did observers; the means were 2.3 and 4.4 , respectively. In contrast, the means for actors and observers in the no-cheat condition were virtually identical, 7.8 and 7.6 , respectively. These findings indicate that cheating was generally attributed to nonpersonal factors, and they are consistent with the main effect of behavior found on the attribution-toexternal-factors item $[F(1,67)=13.38, p<.001]$. Examination of the means indicates that external factors

Table 1

Attributions to Causes From Stage 1 to Stage 6

\begin{tabular}{|c|c|c|c|c|}
\hline \multirow[b]{2}{*}{ Stage } & \multirow[b]{2}{*}{ Noncheating Statement } & \multirow[b]{2}{*}{ Cheating Statement } & \multicolumn{2}{|c|}{ Condition } \\
\hline & & & Not Cheating & Cheating \\
\hline 1 & $\begin{array}{l}\text { I wanted to avoid getting } \\
\text { penalized if caught. }\end{array}$ & $\begin{array}{l}\text { I wanted to avoid getting } \\
\text { penalized for a poor score. }\end{array}$ & $4.03 \mathrm{~d}$ & $4.76_{c, d}$ \\
\hline 2 & $\begin{array}{l}\text { Cheating would not have helped } \\
\text { me get what I wanted. }\end{array}$ & $\begin{array}{l}\text { Cheating would have helped } \\
\text { me get what I wanted. }\end{array}$ & $4.06_{d}$ & $4.13_{\mathrm{d}}$ \\
\hline 3 & $\begin{array}{l}\text { I wanted to be a "good" } \\
\text { subject. }\end{array}$ & $\begin{array}{l}\text { I wanted to be a "good" } \\
\text { subject. }\end{array}$ & $6.05_{b}$ & $5.92_{\mathrm{b}}$ \\
\hline 4 & $\begin{array}{l}\text { There are rules against } \\
\text { cheating. }\end{array}$ & $\begin{array}{l}\text { There are no rules } \\
\text { against cheating. }\end{array}$ & $5.20_{b, c}$ & $2.82 \mathrm{e}$ \\
\hline 5 & $\begin{array}{l}\text { Not cheating was the only way } \\
\text { to make certain the rights of all } \\
\text { concerned were not violated. }\end{array}$ & $\begin{array}{l}\text { Cheating was the only way to } \\
\text { make certain the rights of all } \\
\text { concerned were not violated. }\end{array}$ & $5.35_{b, c}$ & $2.81_{\mathrm{e}}$ \\
\hline 6 & $\begin{array}{l}\text { In this situation cheating would } \\
\text { have been inconsistent with my } \\
\text { own moral principles. }\end{array}$ & $\begin{array}{l}\text { In this situation cheating was } \\
\text { not inconsistent with my } \\
\text { own moral principles. }\end{array}$ & $7.96 \mathrm{a}$ & $4.03 \mathrm{~d}$ \\
\hline
\end{tabular}

Note-Means could range from 1 (completely disagree) to 9 (completely agree); larger scores therefore imply greater causal significance. Means without a common single letter subscript differ at the $p=.05$ level by Newman-Keuls. 
were perceived to be more causally significant in producing cheating than in producing noncheating; the means were 6.5 and 4.0 , respectively.

\section{DISCUSSION}

This research provides insight into the attributional processes that underlie moral judgments. As Kelley's (1971) analysis suggested, moral commendations must, in a sense, be earned by overcoming immoral temptations, but the current research also suggests that moral condemnation must also be earned by behaving immorally when situational pressures are few. In the experimental setting, strong pressures were brought to bear on the individual, and the attributors generally felt that those who fell prey to these pressures were not immoral-but only trying to be "good" subjects. Resisting the temptation to cheat, however, was taken to be evidence of greater moral fortitude, for attributors emphasized the importance of moral principles when explaining not cheating.

Somewhat surprisingly, differences between actors and observers were not that pronounced. Although observers were more likely to suggest that cheating was due to the actor's basic personality characteristics, perspective differences were not found on any of the stage measures or the external-causes item. Although this absence of perspective effects may have been due to the failure to use a yoked observational procedure-whereby each observer would be paired with an actor rather than simply being shown a videotaped simulation-moral judgments may be less susceptible to perspective-produced biases than other attributional inferences. As Kelley (1971, p. 294) noted, individuals generally feel that "what is morally right is a matter of fact" and is therefore characterized by high "consensus among different persons in their reactions." In addition, the pressures to cheat in the experimental setting may have been so powerful that they were as salient to observers as they were to actors.

Lastly, this research suggests that Kohlberg's (1969) stage theory of moral development can be usefully interpreted as a taxonomy of possible explanations of moral and immoral action. Although actors and observers did not differ in their usage of the six stages, the higher stages of the model were more frequently endorsed as explanations of "moral" action, whereas the lower stages of the model were more frequently used to explain "immoral" action. This finding provides support for Kohlberg's interpretation of the stages, but also suggests that his assumption that the stages are content free may be invalid. At least in the eyes of the naive perceiver, good actions are explained more easily in terms of the higher stages, whereas bad actions imply lower stage causality.

\section{REFERENCES}

Kelley, H. H. (1971). Moral evaluation. American Psychologist, 26, 293-300.

KoHLBE RG, L. (1969). Stage and sequence: The cognitive-development approach to socialization. In D. Goslin (Ed.), Handbook of socialization theory and research. New York: Rand McNally.

Ross, M., DiTecco, D. (1975). An attributional analysis of moral judgments. Journal of Social Issues, 32, 91-109.

(Manuscript received for publication March 5, 1984.) 